\title{
Enseñando la guerra: los profesores de educación básica y la guerra de 1879 en la región de Tarapacá en Chile
}

\author{
PATRICIO RIVERA OLGUÍN* \\ Universidad Arturo Prat - Iquique - Chile \\ Recibido el 06-04-2017; primera evaluación el 04-06-2018; \\ segunda evaluación el 11-06-2018; aceptado el 21-06-2018
}

\section{Resumen}

El presente artículo estudia las perspectivas de la enseñanza de la guerra de 1879 que desarrollan los profesores de educación básica de la región de Tarapacá en Chile. En este sentido, los docentes implementan el currículum escolar, textos escolares y sus contenidos para que los estudiantes de educación básica adquieran conocimientos que serán internalizados para la reproducción de la ciudadanía chilena en un espacio que fue conquistado al Perú en la época de la guerra del Pacífico. Estos contenidos constituyen una forma de socializar la identidad nacional chilena y la valoración de acontecimientos y héroes patrios del conflicto con el fin de generar vínculos de identidad y pertenencia al concepto de patria en los alumnos a través de los relatos bélicos.

Palabras clave: enseñanza de la historia, guerra de 1879, profesores

\section{Teaching about the War: Primary school teachers and the 1879 War in the region of Tarapaca, Chile}

\section{Abstract}

The present article studies the perspectives of the education of the war of 1879 that develop the teachers of basic education of the region of Tarapacá in Chile. In this sense, teachers implement the school curriculum, textbooks and their contents so that basic education students acquire knowledge that will be internalized for the reproduction of Chilean citizenship in a space that was conquered in Peru during the war of the Peaceful. These contents constitute a way to socialize the Chilean

\footnotetext{
* Doctor en Didáctica de las Ciencias Sociales y la Historia. (Universidad Autónoma de Barcelona) Académico e investigador de la Facultad de Ciencias Humanas de la Universidad Arturo Prat. Iquique. Chile. Líneas de investigación: Investigación Educativa, Didáctica de la Historia y las Ciencias Sociales, Guerra del Pacífico. Correo: patririv@unap.cl
} 
national identity and the valuation of events and patriotic heroes of the conflict in order to generate identity and belonging links to the concept of homeland in the students through the war stories.

Keywords: teaching history, war of 1879 , teachers

\section{Ensinando sobre a guerra: Professores da escola primária e a guerra de 1879 na regiáo de Tarapaca, Chile}

\section{Resumo}

Este artigo examina o ensino perspectivas dela da guerra de 1879 que desenvolve professores do ensino básico na regiáo de Tarapaca, no Chile. A este respeito, os professores implementar o currículo escolar, livros didáticos e conteúdo para os alunos de conhecimentos básicos de educaçáo adquirem a ser internalizado para a reproduçáo da cidadania chilena em um espaço que foi conquistado Peru no tempo de guerra Pacífico. Estes conteúdos são uma forma de socializar a identidade nacional chilena e apreciação de eventos e heróis nacionais do conflito, a fim de criar laços de identidade e de pertença ao conceito terra natal em estudantes através de histórias de guerra.

Palavras-chave: história do ensino, guerra de 1879, professores

\section{INTRODUCCIÓN}

La práctica pedagógica habitual sobre la guerra de 1879, en los colegios chilenos, se basa en resaltar la gesta bélica, entendiendo el tema histórico como el elemento fundante de la nacionalidad que representa al Estado de Chile. Los contenidos de la guerra de 1879 son el objeto de estudio y el profesor(a) de Historia transfiere el currículum disciplinar y valórico, para que el estudiante se sienta chileno y desarrolle competencias que afirme su identidad nacional, a través del conocimiento del conflicto y, sobre todo, de las figuras de los héroes patrios y de las batallas.

Las propuestas mayoritarias de enseñanza de la guerra del Pacífico en Chile se caracterizan por tener un fundamento nacionalista, desde un prisma de construcción en torno al otro, pero que exalta e incluye al nosotros, como vínculo de entidad nacional y que minimiza, y excluye a la vez, al otro, visto como vencido. Así, se generan elementos de violencia estructural en zonas de frontera, como las regiones de Tarapacá, Arica y Parinacota ${ }^{1}$, en hechos

\footnotetext{
1 Son regiones del extremo norte de Chile, que fueron anexadas al Perú, así como la región de Antofagasta, antiguamente de Bolivia, fueron incorporadas a raíz de la guerra del Pacífico a partir del tratado de Ancón (1883) y de Bolivia (1904).
} 
de antagonismo ritual en las fechas del conflicto (21 de mayo y 7 de junio). Asimismo, la fuerte migración peruana y boliviana, en la región, revive la permanencia de la guerra de 1879 en un espacio que fue campo de batalla.

\section{Marco teórico}

\subsection{La didáctica de la guerra de 1879}

En el caso de la historia y las ciencias sociales, para el mundo escolar chileno, existe un conocimiento de saberes sobre la guerra de 1879 presente en los estudiantes con un carácter muy difundido por los medios de comunicación ${ }^{2}$. Esto ha aumentado, desde 2014, con el Fallo del Tribunal de La Haya y, desde 2015, por la demanda marítima boliviana. Estos hechos provocan una coyuntura en el tratamiento de enseñanza de la guerra en las aulas escolares de la región de Tarapacá y el norte de Chile, dado que se enseña en el mismo sitio de la guerra y en regiones que eran del Perú y Bolivia. Es decir, se enseña en los lugares del conflicto.

Actualmente, existen variadas propuestas de aprendizajes de la historia que están marcados por la asimilación de conceptos más que de hechos cronológicos, situando que la enseńanza de la historia sirva para relacionar el presente con el pasado, formar conciencia histórica y construir otro futuro. Autores como Pagès (2011), Santisteban, González y Pagès (2010) y, en Chile, Oliva (1998) han señalado esta meta en la enseñanza de la historia.

La didáctica de la guerra no tiene mayores especificaciones a nivel de investigación en el continente latinoamericano; sin embargo, han existido algunas referencias bibliográficas destacadas que nacen con el fin de iniciar un proceso de cambio en las perspectivas de estudio de la historia. Los aportes teóricos que existen son de autores como Cavieres (2006) y Cortés (2008); sin embargo, no hay una cantidad apreciable de investigaciones sobre la temática. La investigación de Cortés es innovadora, puesto que consulta a los profesores básicos y estudiantes chilenos sobre la guerra de 1879, mediante metodologías cualitativas, generando una descripción de las percepciones y sus aprendizajes. No obstante, solo demuestra la función de textos específicos de historiadores tradicionales y modernos sobre el conflicto, y su relación con algunos aprendizajes de los estudiantes.

2 En el año 2007 en TVN (Canal estatal de televisión chilena) la serie histórica "Epopeya» que resume la guerra de 1879 y es ampliamente usada por profesores de educación primaria y secundaria como recurso pedagógico. 
Las conclusiones de las percepciones de los estudiantes demuestran el efecto del discurso nacionalista, dado que genera una visión determinada de los vencidos en el conflicto y, a la vez, se produce un efecto de demostración de la inferioridad del otro, en contraposición étnica con respecto al europeo, que se manifiesta en la estética, como en la valoración del otro.

En la perspectiva del historiador Eduardo Cavieres, la reflexión de la enseñanza de la historia de la guerra del Pacífico debe enfocarse hacia la paz y los aspectos históricos comunes de Chile y Perú, como forma de superar los conflictos, antes de sus diferencias de naciones, como de los vínculos aún existentes en este periodo histórico que unen a ambos países.

Entre pensamientos y acciones concretas, el punto principal de las situaciones conflictivas todavía existentes entre Bolivia, Chile y el Perú, a propósito de los aún permanentes efectos de la guerra del Pacífico, está en dilucidar los mejores canales que permitan efectivamente, sin negar la historia de lo sucedido (quizás entendiéndola mejor), poder superar los problemas pendientes para avanzar más decididamente por los caminos de la integración. Todo indica, al parecer, que la historia como disciplina y enseñanza tiene que jugar un papel fundamental en lograr avances precisos en esa dirección (Cavieres, 2006, p. 32).

Es necesario revisar la historia de la guerra del Pacífico en los tres países y sus diferentes versiones, saber cómo se realizan las clases de historia del conflicto y qué se enseña en los países involucrados, enseñar la guerra para la paz y explicar por qué Bolivia pierde el mar y Perú su región sur completa.

La historia de la guerra de 1879, debe ser contada, transmitida y enseńada de otra forma a las que se han utilizado desde el siglo XX en los tres países, se entiende que a pesar del esfuerzo de acercamiento aún subsisten formas excluyentes y aún dogmáticas de mostrar el conflicto, sin extrańar que se muestre entre buenos y malos, dependiendo el bando de las nacionalidad del participante, actualmente hacer clases de la guerra es reproducir el lenguaje militarista ritual de batallas y héroes, sean de vencedores y vencidos (Rivera, 2011, p. 102).

Por tanto, la enseńanza de la historia de la guerra se ejerce mediante fragmentos con mínimo rigor metodológico y entregado a las subjetividades docentes, que, en gran parte, no son especializados y desarrollan reproducciones constantes de los hechos bélicos con el fin de generar valores colectivos de identidad y pertenencia, en los que la palabra patria es reiterada, dado que unifica a todos bajo un mismo lenguaje y ante un mismo enemigo. Esta práctica no es propia solo de Chile, sino que es parte de la identidad militar férrea en los países latinoamericanos, siendo reforzada, en el continente, durante el ciclo de dictaduras militares (1960-1990). Estos ritos y tradiciones son asimilados por los escolares, como ya señalamos. 
En una aplicación didáctica, entendida como el área o espacio de aprendizajes, el estudiante podría asimilar que la guerra se continua en la actualidad, los desfiles, actos cívicos y las conmemoraciones de actividades como el 21 de mayo en Chile o el 8 de octubre en Perú o el 23 de marzo para Bolivia, todas son fechas simbólicas y reflejan ritos del Estado nación que recuerda sus glorias o principalmente sus derrotas que han sido a la larga temporalidad, sacralizadas como forma de continuación que lleve la idea de victoria o de perpetuación de memoria en un ejercicio que es propio de la cultura occidental (Rivera, 2011, p. 119).

La enseńanza de la guerra de 1879 consolida el uso de conceptos como soberanía, héroes, valentía, patria, chilenidad y otras, porque la guerra resume la exaltación de estos conceptos en la mente de los ciudadanos y los insta a transmitirlas; para ello, se hacen desfiles y monumentos con días feriados y celebraciones, mas no se hace lo mismo para recordar las tragedias de los obreros muertos en matanzas, como en 1905, 1907, 1925, 1938 y 1965; por tanto, no hay una paridad en la generación del simbolismo, a pesar de que, en ambos escenarios de conflictos, hubo héroes, aunque los obreros alzados contra el patrón generalmente eran tildados de antipatriotas. Estos hechos, en la historia y su configuración imaginaria, se dejan de lado porque rompen la hegemonía de unidad construida en torno al ideario nacional. En este sentido, no se debe omitir la complejidad de la guerra del Pacífico. Para ello, los escolares y docentes deben conocer la guerra que se libró entre Chile, Perú y Bolivia, desde variados prismas no solo de una nacionalidad, dado que se pierde la dimensión analítica.

El conflicto de 1879 no debe ser evitado, ni tampoco lo debe ser el estudiante que provoca el conflicto; es más, debe ser el aliado en la táctica de abrir el espacio para la interacción, será natural que no exista una obediencia única al proyecto de Integración o que todos compartan la visión, habrán múltiples visiones de un mismo hecho y aparecerán los conflictos aún latentes, las experiencias, los mitos, estereotipos y otras pantallas o canales de una imagen que ha sido congelada por las Historias e identidades nacionales desde 1879. El conflicto es positivo y dinámico, son estados de ánimo de los individuos de cualquier nacionalidad que desean asumir en cualquier escenario con el fin de llegar a una actitud reflexiva. El sujeto o el estudiante debe asumir su conflicto y para ello, debe saber cuál es la causa y eso se conoce a través de una discusión y de confrontación de diversos ángulos de opinión (Rivera, 2011, p. 177). 


\subsection{Las y los profesores básicos en Chile}

La educación básica, antigua primaria en Chile, data de 1840, conocida como sistema de instrucción primaria. Hacia 1860, el Estado se hace cargo de ella como soporte fiscal por medio de la Ley de Instrucción Primaria, haciéndose obligatoria hacia 1920 por la Ley de Instrucción Primaria Obligatoria (LIPO) hasta sexto año de humanidades; sin embargo, con el cambio curricular de 1967, esta se hace obligatoria hasta el octavo año, comenzando en primer año con un rango de edad de 5 a 6 años. Esta etapa educativa es continuadora del nivel de Kinderganden de educación parvularia.

\subsection{La educación y la guerra de 1879 en la región de Tarapacá}

El espacio educativo de la región de Tarapacá está instalado en una constante cobertura de los sucesos del conflicto armado de 1879, conocido en Chile como la guerra del Pacífico y esto se logra a través de una socialización de los hechos bélicos a través de mecanismos como los desfiles escolares ${ }^{3}$, los cuales son masivos en fechas de batallas de la guerra del Pacífico, significativos y recordados en los actos cívicos de los estudiantes todos los lunes de la semana del año escolar. Estas prácticas establecen un culto al Estado y son naturalizadas por las familias, dado que estas han sido normalizadas en este discurso nacionalista de veneración a la Patria y la chilenidad. Esta acción determinó una dinámica de acción nacionalista que se practicaba en el desfile, como en la enseñanza del conflicto bélico de 1879 y tiene sus antecedentes en el proceso de chilenización (González, 2003). Sin embargo, esta práctica aumenta en la dictadura militar (1973-1990), por lo cual, los padres y los escolares son actores y reproductores de una dinámica de acción nacionalista, como el desfile escolar, en un mecanismo de continuidad nacionalista que se implementa en la educación parvularia en la región de Tarapacá (Mondaca Rojas, Rivera Olguín y Gajardo Carvajal, 2014) bajo un sentido de tradición que se constituye en un elemento de identidad nacional y regional.

\footnotetext{
3 En las regiones del extremo norte de Chile; Arica y Parinacota, Tarapacá y Antofagasta, todas conquistadas luego de la guerra de 1879 , se realizan a partir del mes de marzo a diciembre de cada ańo, desfiles cívico-militares en todos los días domingos. En estos desfiles, desfilan ramas de las Fuerzas Armadas y de Orden en conjunto a colegios y jardines infantiles que están de aniversario, la organización de esta actividad está coordinada por la Guarnición Militar de la ciudad.
} 


\subsection{La educación básica, la guerra y la formación de ciudadanías en la región de Tarapacá}

En la educación básica, se instala una enseñanza de la guerra que permite la reproducción del nacionalismo, dado que esta cobertura se establece en un territorio de conflicto en 1879. Esta acción se hace tácita en la formación de la identidad y la ciudadanía chilena en la práctica educativa que desarrollan los profesores de educación básica en la región y es respaldada desde en el currículo y los textos escolares. Ahora, la formación se ve reforzada con los rituales de la guerra de 1879 en las fechas señaladas del conflicto. En coherencia con las dimensiones metodológicas, los profesores de educación básica señalaron sus representaciones, conocimientos, ideas y valoraciones sobre la enseńanza de la guerra del Pacífico.

\section{Metodología}

En la región Tarapacá, existen tres instituciones formadoras del profesorado de educación básica y estas son la Universidad de Tarapacá (estatal), Universidad Arturo Prat (estatal) y Universidad Bolivariana (privada). En Iquique, existen 80 colegios de educación básica en Alto Hospicio, más 24 establecimientos y en las comunas o localidades del interior (rurales) hemos de agregar 10 establecimientos que forman un universo regional de 114 establecimientos ${ }^{4}$. En el caso de estas comunas, suman un universo de 104 colegios. La muestra efectiva de docentes consultados fue 9 , pertenecientes 8 a colegios particulares subvencionados y 1 a una escuela municipal, constituyendo, en total, un $8 \%$ de representatividad del universo regional.

La metodología aplicada es cualitativa y se elaboró un cuestionario de entrevistas semiestructurada de quince preguntas, dividida en dimensiones, a cada docente en forma oral y presencial, bajo condiciones de comodidad en recintos del mismo establecimiento, seguidas de un protocolo de llegada. La aproximación a los entrevistados se realizó mediante llamados telefónicos y correos electrónicos. Respecto a la muestra cualitativa, esta es soportable con relación al universo, dado que se enfoca principalmente a las comunas de Alto Hospicio e Iquique y se profundiza con la cantidad de colegios, porque estos se escogen por la cantidad de estudiantes matriculados, que es un alto número.

4 En la región Tarapacá, existen las comunas de Iquique, Alto Hospicio, Pozo Almonte, Huara, Camińa y Colchane, sin embargo, este estudio abarcó solo las áreas urbanas de mayor concentración de estudiantes de Iquique y Alto Hospicio. 
La codificación fue construida porque los docentes consultados prefirieron omitir sus identidades y colegios de referencia; sin embargo, la cantidad de colegios de Alto Hospicio fue de dos establecimientos, ambos particulares subvencionados y siete de Iquique, de estos, seis particulares subvencionados y uno municipal. El género de los consultados fue asimétrico siendo dos masculinos y siete femeninos.

La codificación fue la siguiente: Colegio Particular Subvencionado Básico se abrevió como CPSB. Se utilizó una correlación según numeración de la entrevista y finalmente el género $\mathrm{H}$ : Hombre y M: Mujer: CPSB-1-H. CPSB-2-H. CPSB-3-M. CPSB-4-M. CPSB-5-M. CPSB-6-M. CPSB-7-M. Colegio Municipal Básico se abrevió como CMB y solo se asignó la numeración 1 y género, resultando como CMB-1-M.

Las dimensiones para sistematizar las preguntas fueron dos:

- Dimensión A: Representaciones y conocimientos curriculares de la guerra de 1879

- Dimensión B: Ideas y valoraciones sobre la enseñanza de la guerra de 1879

Posteriormente, se realizó un proceso de triangulación de los datos y de análisis de las percepciones de los académicos.

\subsection{Dimensión A: Conocimientos curriculares y representaciones de la guerra de 1879}

Los conocimientos y las representaciones de la guerra del Pacífico responden a los saberes que existen de este hecho, no solo son historiográficos, sino también adquiridos desde la novela histórica y el mito. En este sentido, surgen las representaciones que responden a construcciones subjetivas de hechos históricos o culturales. Estas se han ido validando con la experiencia y, en la pedagogía, con su ejercicio continuo sobre los sucesos transcurridos entre 1879 y 1883.

En el aspecto de saberes del conflicto, los profesores señalan el conocimiento de la guerra asociado al relato bélico y describen las campańas militares y las batallas, como los referentes esenciales del suceso histórico.

Conozco los elementos que contribuyeron al inicio del conflicto, cada una de las 5 campańas que se desarrollaron durante la guerra y el proceso que se suscitó en nuestro país (y región, particularmente), una vez concluido el evento (CPSB-1-H). 
A la vez, existen otros que solo expresan una referencia general, muy leve sobre el tema a un nivel de conocimiento superficial.

Es un hecho histórico en el que intervienen Chile, Perú y Bolivia (CPSB-2-M).

Más, otros docentes, a pesar de entregar una referencia genérica al conflicto, ofrecen una mayor profundidad al interpretar el tema bélico, como la motivación económica, evidenciada en el caso de la lucha por el mineral del salitre.

A grandes rasgos, fue un conflicto, en donde participaron Chile, Perú y Bolivia, se le conoce además como guerra del Salitre (CPSB-3-M).

La interpretación supera al discurso formal que señala al conflicto como guerra del Pacífico y este se reemplaza por guerra del Salitre, por lo cual, se entrega una hermenéutica del conocimiento específico del profesor.

De manera general, que ha sido llamada por años guerra del Pacífico, pero en realidad fue un conflicto generado por el Salitre, o sea, es un conflicto económico (CPSB-4-M).

Asimismo, los profesores, refieren elementos descriptores de la historia, como episodios y personajes, asociados a causas y consecuencias.

Las causas, consecuencias y muchos de los episodios históricos y personajes que se destacaron en este evento (CPSB-5-M).

Existen docentes que evidencian un mayor grado de conocimientos sobre el conflicto, en cuanto a años, causas y sus consecuencias, registrando una mayor identidad con el país, dado que adosan las palabras «nuestro» y "ganancia» para referirse al resultado de la guerra, algo congruente con los planes y programas de estudio, que toman estas referencias como resultados de aprendizaje 5 .

La guerra del Pacífico fue un conflicto bélico que llevó a Chile a enfrentarse con Bolivia y Perú, por problemas limítrofes y económicos, tras cuatro años de lucha, nuestro país resultó vencedor. Esto generó múltiples consecuencias tales como la ampliación de nuestro territorio hacia el norte, incorporando Arica, Iquique y Antofagasta al territorio nacional. Asimismo, Chile se quedó con toda la explotación del salitre, lo que trajo enormes ganancias que fueron utilizadas para modernizar la infraestructura del país, entre otras (CMB-1-M).

5 Ver Planes y programas de estudio de Educación Básica. (1998) Ministerio de Educación. Chile. 
En esta línea de análisis, se pueden apreciar las representaciones de los profesores que señalan una opción histórica que es la defensa nacional, para abordar las causas de la guerra a lo que se agregan datos históricos de agresión que no son referidos en las fuentes escolares.

En 1879, Bolivia y Chile tenían fuertes disputas en la región salitrera de Atacama. Bolivia tenía amenazados a los chilenos con expropiar sus salitreras si no pagaban el impuesto de los 10 centavos por los quintales que salían de Antofagasta. Para evitarlo, Chile invadió este puerto el 14 de febrero de 1879. Perú intentó mediar en el conflicto Chile le declaró la guerra por no declararse neutral. Acto seguido, se declararon varias campañas y guerrillas con acuerdos y tratados (CPSB-6-M).

Existen profesores que evidencian su propia historia escolar para explicar el significado del tema en su vida cuando eran niños o jóvenes, por lo cual podemos comprobar la eficacia del currículo y la enseñanza de la guerra de 1879 en el norte de Chile, ya que demuestra la vigencia de estos saberes.

Lo que yo conozco de la guerra corresponde fundamentalmente a lo que me enseñaron durante mi educación media. El cual se trata principalmente de un hecho bélico que involucra a los tres países limítrofes; Chile, Perú y Bolivia. Dónde en consecuencia de una serie de eventos se produce la guerra, entre ellos se menciona la confusión y concordia respecto a los límites de Chile por el norte, la ambición de este por las riquezas presentes en las entonces tierras bolivianas, la violación del tratado por parte de Bolivia al imponer impuestos sobre el salitre, como también el pacto secreto que realizaron los países vecinos Perú y Bolivia, el cual constituía una alianza frente a cualquier amenaza. Gracias al tratado de Ancón en 1883 con el Perú y el tratado de paz con Bolivia en 1904 se obtiene en consecuencia a las 3 naciones como las conocemos hoy en día un Chile extenso, que comienza desde tierras anteriormente peruanas, dueño de las riquezas minerales del norte, supremacía en el desarrollo comercial del Pacífico sur, una Bolivia carente de salida al mar, y un Perú expropiado (CPSB-7-M).

Por tanto, la eficacia de la cobertura curricular y el énfasis en la guerra hace efectivo el discurso de ciudadanía y de soberanía que se socializan en los profesores de los colegios de la región.

\section{Conocimientos curriculares, planes y programas de estudio y la guerra de 1879}

Los conocimientos curriculares se refieren a los contenidos, orientaciones, objetivos y documentos de trabajo sobre la guerra del Pacífico que el Minis- 
terio de Educación ha diseñado a través de sus planes y programas de estudio desde 1997, luego de los ajustes curriculares de 2010, variadas modificaciones, que no han alterado demasiado el sentido de la enseńanza de la guerra de 1879 , que se orienta a generar ciudadanía nacional chilena en los estudiantes de educación básica. Los programas de estudio y textos escolares se suman a los instrumentos y plataformas informáticas del Mineduc (Ministerio de Educación), que nutren a los docentes de variadas herramientas, como www. educarchile.cl y otros sitios asociados a este. Los planes y programas de estudio conforman la estructura del currículum nacional que el Mineduc elabora para las diferentes asignaturas, entre ellas, para Historia, Geografía y Ciencias Sociales, siendo la guerra del Pacífico unidad o contenido de sexto año básico.

Los planes de estudio muestran la relevancia del territorio chileno en su expansión hacia el norte y el sur, al norte por la guerra de 1879, y al sur por la anexión de los territorios mapuches. En torno a este currículum, los profesores de educación básica señalan estos aspectos de expansión territorial de Chile.

Sí, y lo abordan desde la perspectiva de que los estudiantes describan cómo se fue conformando nuestro territorio nacional, identificando los antecedentes de la guerra y las consecuencias de la expansión territorial para nuestro país (CPSB-2-H).

Los docentes explicitan la importancia de la guerra del Pacífico en la formación de los niños y niñas. La figura del profesorado se hace esencial, ya que es quien entrega el enfoque personal o pone un determinado énfasis en lo que enseńa como forma de socialización.

Efectivamente, las bases curriculares abordan la guerra del Pacífico, pero solo en el $6^{\circ}$ ańo básico con una perspectiva totalmente basada en el contenido. No obstante, lo que enseñamos indirectamente en ler año básico sobre la guerra del Pacífico es, netamente, voluntad del profesor y lo relacionamos a los contenidos exigidos por el Ministerio en $6^{\circ}$ básico con el siguiente objetivo de aprendizaje:

Describir cómo se conformó el territorio de Chile durante el siglo XIX, considerando colonizaciones europeas, la incorporación de Isla de Pascua, la ocupación de la Araucanía, la guerra del Pacífico y diversos conflictos bélicos, entre otros factores. Lamentablemente, su propuesta metodológica no contempla la transversalidad de los ciclos más iniciales (CPSB-5-M).

En esa línea de análisis, los planes de estudio se enfocan a la territorialidad y los cambios espaciales del siglo XIX. Por tanto, el estudiante de educación básica conoce que, a través de la guerra de 1879, Chile aumenta su terri- 
torio y anexa todo el norte grande con una extensión considerable de riquezas minerales.

Desde la perspectiva de los hechos en cuanto a batallas y los territorios adquiridos por Chile (CPSB-6-M).

El profesorado también es capaz de observar la parcialidad del enfoque "poco objetivo» de los hechos históricos, como una crítica a la perspectiva nacionalista que defiende el currículum.

Sí, lo hacen. Lo hacen desde una perspectiva poco objetiva, resaltando la postura constante e invariable que ha tenido nuestro país frente al conflicto (CPSB-1-H).

El recuerdo de determinadas fechas se convierte en un elemento central de los aprendizajes que deben realizar los niños y niñas de educación básica, con lo cual puede cuestionarse, incluso, si están aprendiendo el proceso histórico como tal o solamente algunos datos de forma memorística.

Los planes y programas que competen a $1^{\circ}$ y $6^{\circ}$ de educación básica no abordan la guerra de 1879 como tal, sino más bien para ciertas fechas importantes, tales como el 7 de junio y el 21 de mayo se conmemora con una pequeña clase explicativa y actividades relacionadas a esta (CPSB-7-M).

La visión es diversa, porque se mezcla la enseñanza de los hechos históricos con la conmemoración de una fecha simbólica en la región, donde, al ser un día feriado, se activa el aparato del Estado en actos y desfiles en recuerdo de la guerra.

Solo está como efeméride, no dentro de los objetivos de aprendizaje (CM1-M).

Los docentes, dentro de una diversidad de interpretaciones, muestran una tendencia a justificar el currículum como desarrollo de aprendizajes.

$\mathrm{Si}$, los planes los abordan, desde una perspectiva bastante transversal y empática en la cual los estudiantes opinan (CPSB-4-M).

Algunos profesores hacen referencias directas a determinados contenidos, resaltando los elementos de vinculación patriótica y las fechas-efemérides como recurso para el aprendizaje de lo que reclama el texto escolar y los planes de estudio.

Haciendo notar la valentía y valor de los participantes chilenos. Como una fecha, 21 de mayo, sin mayor relevancia. En $6^{\circ}$ básico: como se llega a anexar 
el territorio a Chile [...]. ¿El texto escolar considera la guerra de 1879 y de qué forma lo hace? Lo aborda, como un hecho histórico sobre la base económica del país. Recuerdos y valores de patriotismo, como se inicia el Juramento a la Bandera en la Batalla de la Concepción (CPSB-3-M).

\section{La guerra de 1879 y los textos escolares en Educación Básica}

Para el profesorado, los textos escolares reflejan la historia oficial, dado que su relato es el que el Estado decide que reciban los estudiantes. Los textos escolares de Historia son revisados por entidades del Mineduc, como del Consejo Superior de Educación ${ }^{6}$, por lo cual son contenidos oficiales y adaptados a las pruebas estandarizadas $\mathrm{SIMCE}^{7}$. Por ello, es un texto obligatorio y básico, aunque no recoja, en el caso de historia, cuestiones fundamentales de pensamiento histórico, tal como seńalan los profesores de educación básica, que lo consideran una información sin análisis histórico, que solo hace referencia a acontecimientos sin mayor continuidad histórica o definición de tiempo histórico.

El texto escolar aborda la guerra de 1879; sin embargo, lo hace en forma muy básica, no da oportunidades para generar un análisis histórico de este evento: lo ve como un acontecimiento que ocurrió dentro del período de los gobiernos liberales pasando por alto los verdaderos intereses nacionales que tenía Chile con la guerra (CPSB-1-H).

El texto escolar, según algunos docentes, no tiene contenidos de la guerra de 1879 , solo en el sexto ańo básico, sin embargo, lo hace desde una perspectiva con claro énfasis en las efemérides.

Nuestro texto escolar del Ministerio en primer año básico no lo contempla, pero si observamos el libro de $6^{\circ}$ básico, es un texto totalmente estadístico, con fechas y datos claves de hechos importantes. En ningún momento llama a la reflexión o motiva a los estudiantes a aprender de otra forma, más didáctica y estimulante (CPSB-5-M).

La orientación del texto es el recuerdo de los hechos bélicos para los estudiantes y, específicamente, de las batallas.

${ }^{6}$ El Consejo Nacional de Educación se orienta a cautelar y promover, de manera prioritaria, la calidad de la educación. Desarrolla sus funciones en el marco del Sistema Nacional de Aseguramiento de la Calidad de la Educación Escolar y del Sistema Nacional de Aseguramiento de la Calidad de la Educación Superior. Ver http://www.cned.cl/ consultado el 27 de agosto del 2015.

7 Sistema de Medición de la Calidad de la Educación. www.simce.cl 
Los textos escolares consideran estos hechos como aislados, refiriéndose a un evento en particular, por ejemplo: Asalto y Toma del Morro de Arica (CPSB-4-M).

Para los primeros ańos, no existen textos referidos a la asignatura que aborden la guerra, pero se suple con una presencia significativa de actos de socialización nacionalista, a través de otros contenidos o celebraciones escolares.

No, los contenidos en este caso de segundo básico, no abordan este tema.

Lo que yo hago es tomar la efeméride y articularla con algún otro subsector (CPSB-3-M).

A pesar de todo, los docentes indican que no existen mayores contenidos en los textos escolares sobre la guerra, aunque estos están presentes en los planes y programas de estudio. Entonces, se asiste a un escenario de creencias y representaciones de las y los profesores de historia de la región de Tarapacá, que suma batallas navales y terrestres, y que es manifiesta como parte de la identidad regional, dado que el espacio habitado es producto de una guerra con Perú y Bolivia.

\section{Dimensión B: Ideas y valoraciones sobre la enseñanza de la guerra de 1879: enseñar la guerra de 1879}

La importancia de enseńar la guerra de 1879, como un contenido relevante, adquiere una gran importancia y pertinencia, porque los docentes consideran que el trabajo pedagógico es fundamental para que los estudiantes aprendan del conflicto, como tema de identidad nacional, para educar un modelo de ciudadanía donde la historia muestra un relato oficial y único de la guerra de 1879.

El discurso de carácter guerrero de este currículum se defiende, por parte de los profesores, como una forma de inculcación de la trascendencia de la defensa del territorio, que se mezcla con el respeto al extranjero, en referencia a los residentes.

Sí, porque forma parte de la identidad del chileno, en el cual se incorporan los territorios bolivianos y peruanos a nuestro país y que el niño (a) conozca, valore y se identifique como tal, valorando y reconociendo el valor de dar la vida por su país si es necesario. Además, valorar y respetar al extranjero que vive en el país (CPSB-3-M).

En esta línea de análisis, la identidad nacional es una unidad curricular definida en torno a valores y símbolos patrios, que genera un apego por la idea de país y, en ello, los profesores son claves en el proceso. 
Sí, ya que deben conocer antecedentes históricos y relevantes acontecidos en su pasado, lo cual forma parte de la identidad nacional (CMB-1-M).

La historia enseñada se reduce a contenidos de fechas y cronología histórica para situar las efemérides, sin que exista un planteamiento alternativo de formación del pensamiento histórico en los estudiantes.

Sí, considero relevante para explicar algunas efemérides recordadas durante el año escolar»(CPSB-4-M).

Aunque el aprendizaje se centra en las fechas, hechos y personajes, los profesores consideran de gran importancia conocer los sucesos de la guerra como un camino para la comprensión de la actualidad. Pero el presente está presentado, a la vez, como una consecuencia del pasado, sin una interpretación crítica ni del pasado ni del presente.

Considero que el trabajo pedagógico de la guerra de 1879 es vital para poder comprender los procesos sociales que han construido el Chile de hoy y, particularmente, nuestra identidad como iquiqueños(CPSB-1-H).

La enseñanza de la historia que defienden los docentes está basada en una concepción del peso histórico del espacio. Los docentes explican el territorio como el factor fundamental que influye en la definición de los contenidos escolares en un territorio multicultural en el que conviven diferentes nacionalidades.

Sí considero que es importante abordar pedagógicamente la guerra de 1879, debido a la realidad educativa a la que nos vemos enfrentados hoy en día, sobre todo aquí en Iquique, donde es fácilmente evidenciar, como en las aulas existe una gran variedad de estudiantes de distintas nacionalidades. Diversidad, la cual no tan solo se hace presente dentro del aula sino también en la misma socialización de la región, por lo cual es de suma urgencia que esta temática se haga presente y se desarrolle de una forma pedagógica en las aulas (CPSB-7-M).

Algunos profesores también muestran una actitud crítica hacia una determinada forma de enseñar la historia, basada en la exaltación nacionalista. Este tipo de profesores defiende una historia integradora y que ayude al alumnado a pensar críticamente el relato que se hace del conflicto, resaltando el contexto de la época, para una comprensión del proceso histórico y para generar competencias de pensamiento histórico.

Sí, porque la guerra del Pacífico forma parte de nuestra identidad, y no solo chilena, sino que también peruana y boliviana. Pero, su enseñanza no debe 
estar enfocada hacia una exaltación del nacionalismo, destacando héroes y batallas, sino, más bien, inclusivo, para construir una cultura de paz y entendimiento, haciendo entender a los estudiantes que el conflicto obedeció a un contexto diferente al que tenemos hoy en día, motivando a que los conflictos deben entenderse como algo evitable (CPSB-2-H).

Estas apreciaciones sobre la enseñanza de la historia y sus fines ayudan a comprender la diversidad existente en las aulas de los colegios del norte de Chile, que tienen una cantidad muy alta de estudiantes extranjeros, dibujando un amplio escenario multicultural, con personas de origen diverso que reciben una educación histórica donde se define la zona como región chilena y se justifica sobre la base de un hecho bélico.

Toda enseñanza debe ser pedagógica y no ideológica, es muy relevante que esto último sea cambiado en favor de nuestros alumnos que cada vez llenan las aulas con más diversidad cultural, al provenir de distintos países(CPSB-5-M).

Algunos docentes ponen énfasis en la interpretación de los hechos y de las fuentes, y el desarrollo de competencias de pensamiento crítico en los estudiantes, con el fin de generar otra visión de la historia, distinta de la historia oficial y de la historiografía oficialista.

Creo que sí en el sentido de hacer reflexionar a nuestros jóvenes sobre cómo existe una historia oficial y la otra en que descubrimos que siempre el poder está en manos de unos cuantos (CPSB-6-M).

\section{¿Cuándo enseñar la guerra del Pacífico?}

El momento de enseñar la guerra es una situación que invita al docente a reflexionar sobre su adecuación como contenido escolar a una edad determinada, lo cual es de interés para comprender qué piensan los profesores sobre la enseñanza de la guerra y sus propósitos. Algunos asocian el contenido de la guerra como referente de nacionalidad y piensan en su enseñanza en edades tempranas, como celebración de una efeméride bélica, como proceso de socialización de contenidos.

Las efemérides son una clara oportunidad para poder enseñar a los niños la guerra y sus consecuencias desde pequeños(CPSB-1-H).

Desde el nivel básico (CM1-M).

Se considera, desde esta perspectiva, que las primeras edades son más adecuadas para conocer el conflicto, dado que los aprendizajes serán más 
significativos y mayor el impacto de los conocimientos adquiridos, lo cual, en el caso de la guerra, es muy discutible, aunque depende del enfoque o del uso que se haga de la historia, como adoctrinamiento o como enseñanza de valores.

Desde los primeros niveles, porque es más significativo el aprendizaje (CPSB-2-H).

También se reclama la necesidad de que los conocimientos específicos sobre la guerra, que se enseñan en sexto ańo básico, se adelantaran un año.

Se debería enseñar desde niveles más pequeños como $4^{\circ}$ o $5^{\circ}$ básico (CPSB-3-M).

Existe también la perspectiva de una enseñanza de la historia que sea una formación en valores democráticos, para la convivencia, como el respeto al otro y la tolerancia, como educación para la paz.

Desde los niveles más pequeńos, para formar en ellos niños el respeto, valorar al otro, tolerancia, etc. (CPSB-4-M).

Se manifiesta, también, que la niña o el niño tenga conocimientos del conflicto en clara coherencia con el medio familiar, como un agente vigente en los procesos de formación de ciudadanías en la región norte de Chile.

Desde Transición (Jardín), soy testigo de la motivación que los alumnos tienen por la historia. Les encanta vivir la historia y conocer nuevas cosas. Lamentablemente, se pierde mucho tiempo en enseñar contenidos que los niños ya conocen (ejemplo: «yo soy» unidad donde los nińos reconocen sus características personales). Siento y creo que, si no se motivan a los alumnos en las etapas iniciales de escolaridad, eso influirá en los años posteriores frente a diversas asignaturas. Gran parte de mis apoderados me dicen que no hay asignatura que más les guste a los niños que historia, donde llegan todos los viernes a la casa a contar y debatir con sus padres nuevas experiencias e historias que aprenden (CPSB-5-M).

En este sentido, se invita a considerar los desarrollos afectivos en coherencia con los cognitivos cuando se traten estos temas.

Desde niveles, básicos ajustando a su desarrollo emocional e intelectual (CPSB-6-M).

Desde una posición claramente crítica, solo una docente se manifiesta con preocupación al observar los contenidos sobre al conflicto bélico, que califica 
como excluyentes de los ciudadanos de los países vecinos y que promueven la adquisición de roles militaristas en los estudiantes, la uniformización y que resaltan los hechos bélicos por encima de estos aprendizajes, con la idea del chileno vencedor sobre los vencidos.

A mi parecer, la guerra 1879, como tal, se debiese enseñar con todo el contenido que conlleva en segundo medio, debido a las características que poseen los estudiantes. Pero como es posible observar hoy en día en las escuelas, desde etapas muy tempranas, a los niños ya se le inculca rasgos simbólicos de la guerra, como vestirse de marineros en educación parvularia, y pintar, dibujar y cantar relatos relacionados en educación básica. Es por ello que considero que debiese ser más bien un carácter progresivo, debido a que es un tema que es muy significativo sobre todo para la región de Tarapacá, por lo que de edades tempranas se debiese tratar temas como la integración y el respeto a los demás, evitando las actividades que alaban el conflicto y lo enaltecen con la proclama «los vencedores y vencidos» (CPSB-7-M).

\section{La reflexión sobre la importancia de la guerra de 1879 para el Estado de Chile}

La guerra del Pacífico es un hecho emblemático en las conmemoraciones oficiales del Estado de Chile. Uno de los días feriados más importantes en Chile es el 21 de mayo, día de las Glorias Navales y, en esa fecha, se recuerda el Combate Naval de Iquique. Si se suma a ese día el de las Glorias del Ejército, el 19 de septiembre, fecha que se celebra con una gran parada militar en que una unidad del ejército desfila con uniformes de la guerra de 1879, tenemos el simbolismo creado por el Estado de Chile alrededor de la guerra.

En el caso del contexto educativo, no es ajeno a esta situación y se participa de todas las celebraciones con variadas actividades el mismo día 21 de mayo, como en el mismo mar, que es llamado Mes del $\mathrm{Mar}^{8}$. En especial, en las ciudades del norte, en Arica, Calama, Antofagasta e Iquique, se sitúan en fechas de combates o batallas de la guerra; por tanto, cada celebración local tiene un marcado carácter nacionalista, dado que se recuerda la guerra y, con ello, la anexión de las localidades al Estado de Chile.

\footnotetext{
8 «Bajo la inspiración del entonces comandante en jefe de la Armada, almirante don José Toribio Merino Castro y con el objeto de resaltar en el mes de mayo las gestas heroicas del Combate Naval de Iquique y Punta Gruesa, y el océano como fuente inagotable de prosperidad, en 1974 fue creado el "Mes del Mar», el que a través de su relevante historia ha ido fomentando en la conciencia ciudadana la importancia de este patrimonio, baluarte en el progreso y soberanía de Chile en el Pacífico». En www. mardechile.cl consultado el 01 de septiembre del 2015.
} 
Creo que para el Estado de Chile es muy importante la enseñanza adecuada de la guerra de 1879, pues a través de ella se puede contribuir a la formación de buenos ciudadanos, conscientes de los errores del pasado y dispuestos a aprender de esos errores para contribuir a la convivencia armónica de nuestro continente (CPSB-1-H).

Existe pues una cierta contradicción entre el enfoque nacionalista del currículum sobre la guerra de 1879 y lo que indican los profesores en sus propósitos. La enseñanza de la guerra no tiene por qué avivar el conflicto, parece que se deduce de sus opiniones, pero la defensa del nacionalismo y la celebración de hechos históricos, tal como propone el Estado, no parece ser una solución para promover actitudes nuevas. Al contrario, se considera que la guerra debe tener más presencia en la enseñanza básica, sin que se señalen alternativas a su enseñanza actual.

Debiera darle más realce» (CM1-M).

Los valores patrios son parte de las actitudes que se transfieren a los estudiantes por parte de los docentes, siguiendo el currículum. Se afirma que hay que defender al país con argumentos, pero no se plantea la existencia de otras razones desde otras visiones del conflicto.

Sí, debe serlo porque educando y enseñando valores patrios se ama la tierra en que se nace. Gracias a ello los patriotas respetarán y valorarán al país. También para defender a nuestro país con razones y fundamentos (CPSB-3-M).

Para los profesores básicos, la promoción de los valores nacionalistas es la finalidad clara del Estado, que no cuestionan.

Si para fomentar el nacionalismo (CPSB-6-M).

Encontramos un pensamiento del profesorado muy en consonancia con la posición y propuestas curriculares del Estado. Estos profesores defienden que la enseñanza de la guerra del Pacífico es necesaria para una diferenciación histórica y cultural, que hace a Chile diferente del resto de los países latinoamericanos, incluso superior.

Sí, considero que la enseñanza de la guerra de 1879 es de suma relevancia para el Estado de Chile, ya que, como he mencionado antes, esta constituye un hecho bélico que ha significado y ha sido utilizado como gestor de la identidad nacional, de la raza guerrera, por lo que es de suma importancia para el estado chileno, reproducir la ciudadanía nacional. Es por ello que, en la enseńanza de la guerra de 1879, principalmente, se resaltan héroes patrios con características patrióticas y ejemplos a seguir e hitos históricos que resaltan su heroísmo y 
sacrificio por amor a la patria. También se resaltan las glorias del ejército bajo el lema: 'siempre vencedor, jamás vencido, promoviendo la supremacía respecto a los demás (CPSB-7-M).

Pero, en sentido contrario, existen profesores que señalan que el Estado debería integrar conceptos de historia e identidad relativos a otros países, con los cuales se tiene una historia social compartida y una cercanía cultural con más aspectos de unión que de separación.

Sí, porque como dije anteriormente, forma parte de nuestra historia e identidad. Gracias a la guerra, nuestro país se expandió territorialmente, convirtiéndose en una "potencia» del Pacífico Sur, por adueñarse de los territorios donde se explotaba el salitre, lo que provocó que nuestro Estado modernizara su infraestructura, que los obreros se organizaran para exigir mejores condiciones de vida y laborales, etc. Pero, en la práctica, es un contenido más, porque falta la parte reflexiva que es construir una cultura de paz y no exaltar el amor a la patria, ya que la guerra del Pacífico no es el único proceso histórico que nos une con Perú y Bolivia (CPSB-2-H).

En esa línea de análisis aparece una visión más integradora de la ciudadanía y los valores sociales.

Sí, ya que debemos entregar una enseñanza integral a nuestros ciudadanos (CPSB-4-M).

Como una visión alternativa a las expuestas, hay profesores que consideran que el Estado no ha tenido una incidencia clara en la enseńanza de la guerra de 1879 y que no existe una mayor voluntad para dedicar una mayor atención, ya que no se han creado materiales específicos ni ha habido grandes cambios en la forma tradicional de enseñar la guerra.

No mucho, este contenido ha sido abordado en los últimos años de la misma manera. Ha pasado por diversas reformas y actualizaciones de las bases curriculares que no han demostrado una trascendencia importante en los alumnos en generar conciencia de reflexión y análisis. Siento y creo que las clases de historia, en especial con estas fechas, son clases totalmente expositivas ya que el ministerio tampoco ha desarrollado nada por crear una transversalidad con otros contenidos o ańos. Es cosa de ver los libros del ministerio, solo datos y registros (CPSB-5-M).

\section{Estrategias para la enseñanza de la guerra del Pacifico}

La propuesta metodológica para una enseńanza de la guerra de 1879, muestra el modelo del docente para enseńar el conflicto. En este aspecto, el currículum 
orienta actividades, como el mismo texto escolar lo hace; sin embargo, los docentes establecen estrategias de enseñanza elaboradas por ellos. En este sentido, se pretende que se evidencien formas de enseńanza efectivas para el aprendizaje de la guerra, para comprender el ambiente de las clases y la forma en que estas se realizan en los respectivos establecimientos.

Las maestras y maestros de educación básica implementan metodologías diversas según tendencias didácticas e ideología en relación con los valores a enseñar, ya sean el nacionalismo, el militarismo o la tolerancia hacia el otro. Existen profesores que pretenden desarrollar un enfoque plural del conflicto, en oposición a versiones únicas de la guerra.

Analizando diversas posturas en torno al tema, reconocer el sentido más puro de nuestra enseñanza sobre guerra y compararla con la de nuestros países vecinos. Interiorizarse en los orígenes del conflicto, en el desarrollo de este y las consecuencias que tuvo la guerra, pero desde el punto de vista de cada uno de los países en conflicto. Reflexionar sobre cada una de las posturas y comprender, objetivamente, el valor sociocultural que tuvo este evento para nuestro continente (CPSB-1-H).

Hay testimonios de docentes que son difusos, ya que presentan un proyecto de «diversidad» que, en realidad, no implementa tal objetivo, sino que atiende a la unidad nacional y a una valoración icónica de la guerra, centrado en el buque chileno hundido en el combate naval de Iquique que, incluye, incluso, el Himno de la Marina de Chile.

Como un Proyecto de Aula. Ejemplo: «Unidad en la diversidad»

Objetivo: Conocer, rescatar y valorar la identidad nacional, mediante actividades lúdicas y significativas.

Algunas actividades serían: Una salida a terreno a la réplica de la corbeta Esmeralda en Lenguaje.

Crear una corbeta Esmeralda con material de desecho, en Artística.

Medir la longitud de la corbeta en Matemática.

Cantar el himno Brazas a ceñir, en Música, etc. (CM1-M.

Otras propuestas son más coherentes cuando proponen la integración y la enseñanza de la guerra para educar en una cultura de la paz.

Con diversas fuentes, tanto escritas como no escritas, que incluyan las visiones de Chile, Perú y Bolivia, para desarrollar una mirada más integradora sobre el tema, a través de la crítica y la reflexión de los propios estudiantes, pero enmarcado hacia la construcción de una cultura de paz y entendimiento por sobre la exaltación del nacionalismo o el amor a la patria, tendencia que se viene repitiendo hace bastantes años (CPSB-2-H). 
Hay docentes que demuestran un gran conocimiento de los contenidos y del currículum, con una secuencia en el plan de clase dispuesto, que demuestra que se siguen claramente los lineamientos del Mineduc para generar identidad nacional.

\section{$\underline{\text { Inicio: }}$}

Presentar unos videos geográficos a partir de los pueblos originarios hasta resaltar 1879-1900 y hoy.

Comentar los mapas, personas, vestimentas, costumbres, etc.

Desarrollo:

Presentar en PowerPoint el desarrollo económico de los países afectados y explicar sobre el salitre $\mathrm{u}$ oro blanco; sus funciones, servicios y riquezas

Comentar algunos tratados entre Chile-Bolivia sobre el salitre y el guano

Comentar cómo se repartían las riquezas que se obtenían

Anotar qué desacuerdo tuvieron y por qué

Cierre:

Qué consecuencia llevo estos desacuerdos y que ocurrió.

En dos horas más de clases

Retomar lo visto y hacer un cuadro de resumen

Analizar con mapa en mano cómo cambia el dominio del país

Ver por video hasta donde llega Chile dentro de Perú y Bolivia defendiendo y atacando en el nombre de Chile

¿Que se ganó?

¿Que se perdió?

¿Qué hicieron los chilenos en territorio extranjero? Y ¿Cómo se reaccionó en Chile y qué medidas se tomaron?

Visto y analizado ello valorar los grandes personajes que tomaron parte en este conflicto económico que se transformó en político. Conocer las batallas y combates y dar el realce al valor patriótico en hechos o batallas destacados. Este hecho debe ser transversal y tratarse como corresponde no como algo que ocurrió sin valor (CPSB-3-M).

Asimismo, existen registros de profesores que apuntan al desarrollo de competencias analíticas de la historia y para el pensamiento histórico.

A través del juego de roles, asignándoles personajes y comentándole las problemáticas que pueden vivir. De esta manera, potenciamos el debate, análisis y creación de sus propios puntos de vistas sobre la historia. Pero lo más importante es tener esta metodología en una sola línea que sea abordada en todos los cursos de la misma manera, sin evitar la reflexión para los alumnos, dejar de ser expositivos y que ellos desarrollen su propio punto de vista (CPSB-5-M).

Contando con los ausentes de siempre: los y las profesores que están en aula y que vemos cada día la evolución de nuestros niños y jóvenes (CPSB-6-M). 
Hay metodologías sugeridas que buscan un aprendizaje basado en la comprensión, con voluntad de generar empatía y pensamiento histórico.

Las metodologías que se podrían utilizar para la enseñanza de la guerra, podrían ser la investigación guiada, mesas redondas, debates, juego de roles, entrevistas a la población, proyectos de resolución de conflictos, etc. Todas con un propósito de descubrir y analizar las distintas versiones que existen, como también ponerse en el lugar del otro, comprender las problemáticas que perciben, del mismo modo ser capaces de emprender soluciones desde un nivel personal hasta un nivel macro dentro de su entorno (CPSB-7-M).

La empatía se convierte en un aspecto fundamental del pensamiento histórico para el estudio de la guerra de 1879 para conocer al otro y superar las ideas preconcebidas.

Presentando la información desde el punto de vista actual, con preguntas como ¿qué harían ustedes si pudieran viajar al país vecino, como turistas? (CPSB-4-M).

El relato de los docentes es manifiesto: la guerra es parte del discurso de la enseñanza de la historia que se suma al currículum de esta y las estrategias para la enseñanza deben desarrollar la reflexión y el análisis de los hechos para generar la comprensión como forma de entendimiento en la sala de clases y en la cotidianidad social de una región de frontera.

\section{Conclusiones}

Esta investigación se basó en conocer cómo ven los docentes de educación básica la enseńanza y el aprendizaje de la guerra en la escuela, centrada en Chile; sin embargo, puede ser extensiva a Perú o Bolivia. Es evidente que la visión del conflicto está mediada por la idea de cada docente de acuerdo a su contexto o ideología. En este sentido, se analizó cómo el profesorado de educación básica interpreta la guerra para enseñarla, cómo traspasa sus sentimientos hacia este conflicto de la historia de Chile, señalado como uno de los más importantes desde la Independencia del Reino de España.

En los maestros y maestras de educación básica, es importante la idea del otro en esta enseńanza, formada, también, por la influencia de la historia de la guerra, que convive, al mismo tiempo, con intenciones de integración, ya que en la región norte se cuenta con un gran tránsito y presencia de peruanos y bolivianos. Y no solo es relevante la atención del profesorado a los estudiantes, sino que también debe tenerse en cuenta el contacto con los padres o 
apoderados de estos. Por otra parte, el contexto también es educativo y todos viven en una comunidad donde la guerra está presente en el recuerdo de la historia y en los actos cívicos de los colegios todos los días lunes.

La zona de frontera es un espacio híbrido, en términos culturales, que nutre la región y que, en la interacción social cotidiana, en la frontera política, existe una integración cultural y un conocimiento del otro a nivel cotidiano, que favorece la superación del discurso histórico de la guerra.

La inclusión de los contenidos de la guerra del Pacífico en la educación básica se hace, en general, en coherencia con los planes y programas de estudio del currículum educativo nacional para la formación de la ciudadanía chilena con fines de construcción de identidad. Los contenidos de historia de Chile y de la guerra están presentes en los diferentes niveles de primer y segundo ciclo de formación básica. Por tanto, las profesoras y profesores de educación básica que imparten la asignatura de historia de Chile, lo hacen sobre la base de lo que el currículum expresa y teniendo muy en cuenta las pruebas estandarizadas que se deben afrontar cada año. Asimismo, los docentes seńalan que existe una voluntad de profundizar en el conocimiento de la guerra, porque la historia ha sucedido en el espacio que se habita; por tanto, se relaciona la identidad regional del norte con la historia local como parte relevante del relato histórico y la trascendencia de un feriado nacional para todo el Estado por unos hechos históricos localizados en la región norte.

En sí, la valoración de los hechos bélicos ilustra el impacto de la tradición creada, forma parte de las instituciones educativas y se transforma en actividades significativas y fechas simbólicas de batallas y combates, asociados al lugar en que se habita y se educa, constituyéndose en reproductores de la ciudadanía y en los conocimientos e imaginarios de la guerra de 1879. Del mismo modo, desarrollan contenidos y representan la guerra desde su imaginario identitario de carácter nacionalista, con la idea de Estado nacional que se consolida como referente constante de soberanía en el norte de Chile, por lo cual son agentes de reproducción cultural chilena en un territorio que no era chileno y debe ser chilenizado.

En esta línea de análisis, el conocimiento del conflicto bélico es relevante para la identidad de los estudiantes y es parte del relato histórico. A la vez, en la dimensión de enseńanza de la guerra de 1879 , se han podido comprobar los discursos o relatos orales que aportan a la socialización del conflicto, respecto al culto a la patria y sus héroes. Por tanto, el docente es un agente eficiente en el proceso de enseñanza. La identidad regional y aun la local, tributan en afectividad emocional al Estado nacional, por lo que existe una relación que hace que ambas identidades se relacionen y complementen. Esta interacción en el 
norte de Chile tiene su tradición histórica como espacio de conquista chileno a través del conflicto, pero marca también un problema limítrofe que databa de 1840. Por tanto, la guerra legitima la anexión del territorio de Tarapacá, Arica, Antofagasta y Calama y esto fue transferido a los estudiantes.

La dimensión curricular establece el análisis de los contenidos disciplinarios, sus objetivos y actividades sugeridas en el currículum nacional, a través de los planes y programas de estudio: son el relato oficial. Este es congruente con los textos escolares de educación básica donde solo en sexto año básico se trata al tema de la guerra del Pacífico con especificidad. Pero la profundización del enfoque histórico la hacen los profesores, con una gran carga de intencionalidad. La enseńanza de la guerra de 1879 debe ser impartida a edades tempranas, según los docentes. En este aspecto, la mayoría de los profesores y profesoras señalan que los contenidos de la guerra deben ser conocidos por los alumnos de cursos iniciales, con el fin conocer los hechos bélicos, nuevamente en concordancia con la identidad regional y nacional, constituyendo una formación de continuidad en la identidad nacional desde la educación infantil.

Los profesores de educación básica consideran que es importante para el Estado de Chile que los contenidos de la guerra del Pacífico sean transferidos a los estudiantes de educación básica, dado que se modelan como ciudadanos chilenos y la guerra es el hecho histórico ícono de nacionalidad, como los héroes que protagonizan los combates y batallas.

En este sentido, la dimensión aborda la vinculación de los contenidos de la guerra con los aprendizajes y la identidad en el espacio, hay una unión con la identidad nacional que hace conciencia, en los estudiantes, del valor que el territorio del norte tiene para Chile, como de la importancia de la frontera. En este aspecto, algunos docentes también hacen esfuerzos de integración y cercanía hacia los ciudadanos de los países vecinos con el desarrollo de actitudes y valores de tolerancia y el respeto hacia los demás.

Los profesores de educación básica desarrollan un discurso oral como poseedores de una verdad, legitimada por el currículum. Estos explican la temática de la guerra de 1879 con sus propias interpretaciones, que son variadas y responden al contexto cultural. Es por esto que los docentes ponen énfasis en aspectos disímiles, dado que implementan el currículum, pero, a la vez, cuando este no existe, incorporan la temática de la guerra de 1879 en los primeros años de educación básica, porque la socialización ciudadana y los rituales de la guerra están muy presentes. Por tanto, el docente enseńa la guerra de 1879 a sus estudiantes, promoviendo contenidos que tienen 
enfoques nacionalistas, como a la vez otros docentes desarrollan explicaciones que acercan al estudiante a desarrollar el pensamiento histórico y crítico.

En las metodologías de enseñanza se evidencian variados enfoques en la aplicación. Los docentes también señalan que no poseen las técnicas para enseñar la guerra de 1879 y se demuestra que existe una mínima y casi nula formación en esta temática, que genera tensiones a nivel de ciudadanías en contextos de diversidad cultural. Sin embargo, la frontera no es solo recuerdo de la guerra, sino integración en la vida cotidiana, que surge en la interacción entre las ciudadanías y en las escuelas, sobre todo con los estudiantes inmigrantes, que provocan que el profesor o profesora, tenga en consideración estrategias alternativas en la clase, con propuestas que también aluden a competencias de pensamiento histórico y crítico, para entender y comprender al otro, y para desarrollar conciencia histórica.

Actualmente, se viven tiempos de integración, pero son un proceso que, si bien avanza en lo económico, aún tiene obstáculos en la cultura, dado que es un factor que nos distintivo, porque la historia tributa a las configuraciones culturales que se tienen del vecino habitante. Sin embargo, en la región de Tarapacá, antiguo territorio peruano y luego conquistado por Chile, en el cual hubo un protagonismo histórico de héroes y batallas por ambos bandos y que tiene enormes recursos económicos y es hoy la frontera, las y los profesores de historia se desplazan ante un simbolismo que existe, basado en el culto a la guerra y lo nacional.

\section{REFERENCIAS BIBLIOGRÁFÍCAS}

Cavieres, E. (2006). Chile-Perú. La historia y la escuela. Conflictos nacionales. Percepciones sociales. Valparaíso: Ediciones Universitarias de Valparaíso. Pontificia Universidad Católica de Valparaíso.

Cortés, G. (2008). La guerra del Pacifico: los graves errores en la enseñanza de la historia y su distorsión en los sistemas educativos en Chile, Perú y Bolivia. http:// antroposmoderno.com/antro-articulo.php?id_articulo $=1116$

González, S. (2003). Chilenizando a Tunupa. La escuela pública en el Tarapacandino 1880-1990. Santiago: Centro de Estudios Barros Arana.

Ley de Instrucción Primaria Obligatoria (1920). Ley 3.654. http://www.memoriachilena.cl/602/w3-article-8876.html

Mondaca Rojas, C., Rivera Olguín, P. y Gajardo Carvajal, Y. (2014). Educación parvularia e inclusión en el norte de Chile: Formando pequeños chilenos en las aulas de Tarapacá. Alpha (Osorno), (39), 251-266. https://dx.doi. org/10.4067/S0718-22012014000200017 
Pagès, J. (2011). Quelle est la place de l'identité national dans les apprentissages des élèves en histoire? Le Cartable de Clio, 11, 174-181.

Ministerio de Educación (1998). Planes y Programas de Estudio.

Oliva, M. (1998). En el espacio didáctico de una historia viva. Santiago, Chile: Universidad Católica Blas Cańas, Dirección de Investigación y Extensión.

Rivera, P. (2011). La guerra de 1879 y la integración desde la enseńanza de la historia. Gobierno Regional de Tarapacá.

Santisteban, A., González, N. y Pagès, J. (2010). Una investigación sobre la formación del pensamiento histórico. R.M. Ávila, P. Rivero, P.L. Domínguez (Coords.), Metodología de investigación en Didáctica de las Ciencias Sociales. Zaragoza: Institución Fernando el Católico. Diputación de Zaragoza/ AUPDCS. 